\title{
Shooting the messenger: the erosion of trust in science and what to do about it
}

\author{
John Burrage
}

Published online: 6 March 2015

(C) Australasian College of Physical Scientists and Engineers in Medicine 2015

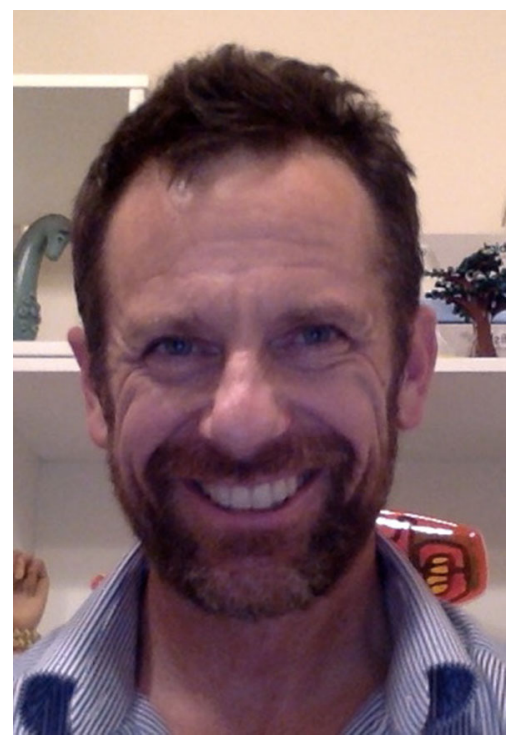

In the last few weeks I have been involved in several radiation safety education sessions at Perth's newest hospital, Fiona Stanley. Although the vast majority of attending staff take a fairly sensible approach, there is often a small group that appear slightly apprehensive or distrustful of the presented material. The tone seems to be; what are you hiding? Why won't you confess that all radiation is terribly dangerous? We don't trust you!

So what do we make of this? By itself; not much, there have always been malcontents. However, I believe it is not inconsistent with a phenomenon happening on a larger scale;

J. Burrage $(\bowtie)$

Royal Perth Hospital, Perth, Australia

e-mail: John.Burrage@health.wa.gov.au

J. Burrage

Fiona Stanley Hospital, Murdoch, Australia the subjection of scientific credibility to unprecedented pressure. I contend that the evidence is ample; it is becoming harder and harder to read a newspaper or surf the net without reading of a dispute over what was thought to be an accepted scientific position. The logical consequence of this constant doubting is a gradual erosion of the general public's trust of science and scientists. Some might regard medical engineering and physics as being insulated from many of the current scientific controversies and hence not worth worrying about. However, I would regard all branches of science as being more or less in the same boat, and any attacks on science in the public eye affects us all to some degree.

Although scientific controversy has a long and proud history that probably began with Galileo in 1610, the first incident bearing the hallmarks of current controversies arguably occurred in 1962 with the publication of Rachael Carson's 'Silent Spring'. The book cautioned against the 
indiscriminate use of DDT and is widely hailed as starting the modern environmental movement. I think it would be quite apparent to anyone who has read the book that it has a careful and measured tone, yet Carson was immediately subjected to fierce attack; representatives from major chemical companies openly criticised her arguments, her understanding of the science, her motives, her qualifications, and her lack of a husband or children [1]. The controversy continued into the late nineties when a group called The Advancement of Sound Science Coalition (TASSC), partially funded by tobacco giant Philip Morris, launched a campaign designed to attack the validity of a host of scientific studies. Although primarily concerned with tobacco, the group also campaigned against the ban on the nonpublic use of DDT and the issue quickly moved from the fringe to the mainstream of US politics [2].

The parallels between the DDT and climate change issues are quite striking. The climate change issue is certainly divisive, with plenty of strong, conflicting viewpoints in the community. There has been ample exposure of both sides of the argument via traditional media but if we restrict our focus to hard science, one would expect the exchange of ideas to occur almost exclusively through peer-reviewed literature. Instead, articles casting doubt on the science are often disseminated through the internet and traditional media via (for example) opinion editorials. A 2012 study found that "Australia's largest circulation newspaper ... is its most sceptical. $67 \%$ of the paper's coverage of climate science did not accept the scientific consensus" [3]. The internet is also an important tool in promulgating uncertainty; a typical site is Climate Depot. Part financed by Chevron and Exxon, it is a grab-bag of articles casting doubt on climate change science [4]. The debate has also seen personal attacks on scientists. Michael Mann, populariser of the so-called hockey stick graph of global temperature variation, is currently embroiled in a court case against an author who accused him of fraud, and also included a quote in the same article suggesting Mann's actions were comparable to those of Jerry Sandusky, a convicted child molester.

So what of this onslaught of bad press? Anecdotally, it would seem some at least some members of the public have completely lost all trust in climate scientists. I was discussing this recently with a reasonably intelligent person who opined that climate scientists were all "crooks and frauds", promulgating lies so they could "become millionaires from their grant money".

Heated debate is not restricted to climate change. Presently there is a small but significant drift away from the practice of vaccination, particularly in the US where, like climate change and DDT, it has moved into the mainstream of federal politics
[5]. In 2012, senator Michelle Bachman went on the public record stating " $[\mathrm{s}]$ he said her daughter was given that vaccine [and] suffered mental retardation as a result. There are very dangerous consequences". Similar statements have been put forward this year by Senator Rand Paul and New Jersey Governor Chris Christie. All this juxtaposed on a US outbreak of measles, a disease with a vaccine. More than 100 cases have been diagnosed in the current outbreak [5]. It should be noted that the debate is also relatively current in Australia; SBS ran a documentary in 2013 addressing the issue which inspired a number of public forums.

In Australia there are also other, sometimes subtle, indicators of a gradual erosion of respect for science. We do not have a minister for science. It was announced earlier this year that the CSIRO would have its funding cut by over $\$ 100$ million over the next 5 years. Major Queensland centres such as Cairns and Bundaberg do not have a fluoridated water supply [6].

So, is this a new phenomenon? No, as we have seen it has been going on since at least the 60's. But what I would argue is the strength and depth of the attack (if "attack" is not too strong a word) is unprecedented. The question is, how best to address it?

I would suggest that on the whole, scientists need to place greater importance on our communication skills. I have had the privilege of working with senior medical physicists in Perth who, aside from being outstanding scientists, are also excellent communicators and I have seen first-hand how effective it can be. We also need to become more proactive about engaging with the public. In the past, we may have believed that scientific evidence would carry the day, and all we need do is wait patiently until the facts prevailed over falsehoods. I do not believe this is a good strategy in the current atmosphere (if indeed, it ever was). Scientists need to be more willing to argue their case, and actively present the evidence to the public. We must be willing to enter debates, and we must be willing to explain the science in a manner that is easily understood by laypeople.

I don't know if the same is true of New Zealand, but in Australia there is a phenomenon known as the 'Tall Poppy Syndrome' - a notion that we try to diminish anyone who becomes too successful. I do not believe this is so; there are plenty of respected, successful Australians. What I do believe, though, is that as a fairly egalitarian society, we Australians have always had a serious mistrust or dislike of a person we perceive as thinking they are 'better' than us. Compare this to the UK, where the notion of class or breeding is heavily ingrained into societal dynamics. To come across as aloof or superior in Australia is virtual social suicide, and we have always been more accepting of people we perceive to be, at heart, "one of us". Too much 
is made of scientists in their "ivory towers"; we need to let the public know that is not the case. (Unless some colleagues actually do work in an ivory tower, in which case please let us know what it's like).

We also need to be as honest and be as up front as possible. It is a sad fact of life that someone who is "confidently wrong" will find more favour with the layperson that someone who is cautiously right, one of the defining characteristics of the scientist. However, I think this is a short-term gain, long term loss strategy. Ultimately too many wrong predictions will completely erode one's credibility, and if there is a need to equivocate, then we should do so, but at the same time be clear about why we are doing so. We should also not be afraid to admit when we are wrong, and to try new approaches. But ultimately I think we need to engage with the public; show them we are not so different, it's just that we spend an awful lot of time doing science, know what we are talking about, and in general, can be trusted.

\section{References}

1. Rupke NA (ed) (2009) Eminent lives in twentieth-century science $\&$ religion, 2nd edn. Peter Lang, Frankfurt

2. Quiggen J (2008) Rehabilitating Carson. http://www.prospectma gazine.co.uk/magazine/rehabilitatingcarson. Accessed on $22 \mathrm{Feb}$ 2015

3. Bacon W (2013) Big Australian media reject climate science. http:/www.australasianscience.com.au/article/issue-november-2013/ big-australian-media-reject-climate-science.html. Accessed on 22 Feb 2015

4. Sharmer M (2015) What can be done about peudoskepticism? http://www.scientificamerican.com/article/what-can-be-done-aboutpseudoskepticism/. Accessed on 22 Feb 2015

5. Foster P (2015) Measles outbreak deepens in US as vaccine debate gets political. http://www.telegraph.co.uk/news/worldnews/north america/usa/11388003/Measles-outbreak-deepens-in-US-as-vac cine-debate-gets-political.html. Accessed on 22 Feb 2015

6. Howells M (2014) Chief dentist pushes councils to add fluoride to water supply as Child Oral Health Survey confirms benefits. http:// www.abc.net.au/news/2014-08-05/qld-survey-confirms-fluoride-sig nificantly-reduces-tooth-decay/5648666. Accessed on 22 Feb 2015 